\title{
Movement patterns of the European squid Loligo vulgaris during the inshore spawning season
}

\author{
Miguel Cabanellas-Reboredo ${ }^{1, *}$, Josep Alós1, Miquel Palmer ${ }^{1}$, David March¹, \\ Ron O'Dor ${ }^{2}$
}

\author{
${ }^{1}$ Instituto Mediterráneo de Estudios Avanzados, IMEDEA (CSIC-UIB), C/ Miquel Marques 21, 07190 Esporles, Islas Baleares, Spain \\ ${ }^{2}$ Biology Department of Dalhousie University, Halifax, Nova Scotia B3H 4J1, Canada
}

\begin{abstract}
In the Western Mediterranean, the European squid Loligo vulgaris is exploited by both commercial and recreational fleets when it spawns in inshore waters. The inshore recreational fishery in the southern waters of Mallorca (Balearic Islands) concentrates within a narrow, well-delineated area and takes place during a very specific period of the day (sunset). Another closely related species, $L$. reynaudii, displays a daily activity cycle during the spawning season (feeding at night and spawning in the day). Using acoustic tracking telemetry, we tested the hypothesis that $L$. vulgaris could display a similar daily activity pattern. We conducted 2 tracking experiments during May to July 2010 and December 2010 to March 2011, in which a total of 26 squid were tagged. Our results suggested that $L$. vulgaris movements differ between day and night. The squid moved within a small area during the daytime but covered a larger area from sunset to sunrise. The probability of detecting squid was greatest between depths of 25 and $30 \mathrm{~m}$. The abundance of egg clutches at this depth range was also greater than at the other sampled depths. The distribution of the recreational fishing effort using line jigging, both in time (at sunset) and in space (in the 20 to $35 \mathrm{~m}$ depth range), also supports the 'feeding at night and spawning in the day' hypothesis.
\end{abstract}

KEY WORDS: Acoustic telemetry $\cdot$ Cephalopod $\cdot$ Daily activity cycle $\cdot$ Recreational fishing effort . Egg clutch distribution

\section{INTRODUCTION}

The European squid Loligo vulgaris Lamarck (1798) is targeted in the Mediterranean Sea by both commercial and recreational fishers (Guerra et al. 1994, González \& Sánchez 2002, Morales-Nin et al. 2005). This species has a high socio-economical value and thus experiences large fishing pressure (Guerra et al. 1994, Ulaş \& Aydin 2011). Most of the life-history traits of this species are known (Guerra 1992, Guerra \& Rocha 1994, Moreno et al. 2002, 2007, Šifner \& Vrgoc 2004). However, knowledge on the spatial and temporal patterns of habitat use by $L$. vulgaris is still scarce and remains elusive, despite the relevance of such knowledge for assessing and managing fishery resources (Pecl et al. 2006, Botsford et al. 2009).
One of the movement patterns that has potential outcomes on fishing success is the inshore-offshore seasonally periodical movement. This type of movement has been repeatedly described and related to reproduction and feeding cycles in other cephalopods (Tinbergen \& Verwey 1945, Worms 1983, Boyle et al. 1995), and it has been suggested that Loligo vulgaris would display this pattern (Sánchez \& Guerra 1994, Šifner \& Vrgoc 2004). Large mature or premature individuals are abundant in shallow coastal waters, likely for mating and spawning; the new recruits appear to hatch near the coast and subsequently migrate towards deeper waters (Guerra 1992, Sánchez \& Guerra 1994).

The outcome of such an abundance pattern is the development of a seasonal fishery for Loligo vulgaris 
when large squid are abundant close to shore. Nearshore spawning aggregations of other Loligo species are typically exploited using line jigging (Augustyn \& Roel 1998, Hanlon 1998, Iwata et al. 2010, Postuma \& Gasalla 2010). In inshore waters near Mallorca (Balearic Islands), other commercial gears, including seine and trammel nets, sporadically capture squid as very valued bycatch (Cabanellas-Reboredo et al. 2011). However, the main gear for squid is line jigging, which is extensively used by both commercial (artisanal) and recreational fishers (Guerra et al. 1994, CabanellasReboredo et al. 2011). Artisanal handline jigging typically takes place at fishing grounds located between 20 and $35 \mathrm{~m}$ in depth, at night, and with the use of lights. Recreational fishers use line jigging at the same fishing grounds but only at sunset (Cabanellas-Reboredo et al. 2011). The use of light is forbidden for the recreational fleet. However, recreational fishers also fish for squid after sunset by trolling, between the shore and a depth of $10 \mathrm{~m}$ (Cabanellas-Reboredo et al. 2011) close to the illuminated shore of Palma de Mallorca.

Acoustic tracking telemetry has been used to describe the movement patterns of other cephalopod species (Stark et al. 2005, Payne \& O'Dor 2006, Semmens et al. 2007, Dunstan et al. 2011) and to investi- gate the environmental cues of squid movements (Gilly et al. 2006). In addition, acoustic tracking has been used to describe the relationship between metabolic rate and behavior (O'Dor et al. 1995, O'Dor 2002, Aitken et al. 2005) and to improve fisheries management (Pecl et al. 2006). The movement patterns during spawning aggregations of Loligo reynaudii Orbigny (1845) and their relationship with environmental variability have been demonstrated by means of acoustic telemetry (Sauer et al. 1997, Downey et al. 2009). With this background, the specific goal of our study was to use acoustic tracking telemetry to (1) provide the first description of the movement of $L$. vulgaris during the inshore spawning period and (2) relate such a movement pattern to the spatiotemporal distribution of the fishing efforts.

\section{MATERIALS AND METHODS}

\section{Experimental design}

We completed 2 acoustic tracking experiments (ATEs) in the southern waters of Mallorca (Northwest Mediterranean; Fig. 1) during the 2 main spawning seasons of the species (winter and spring to early summer; Guerra \& Rocha 1994, Šifner \&

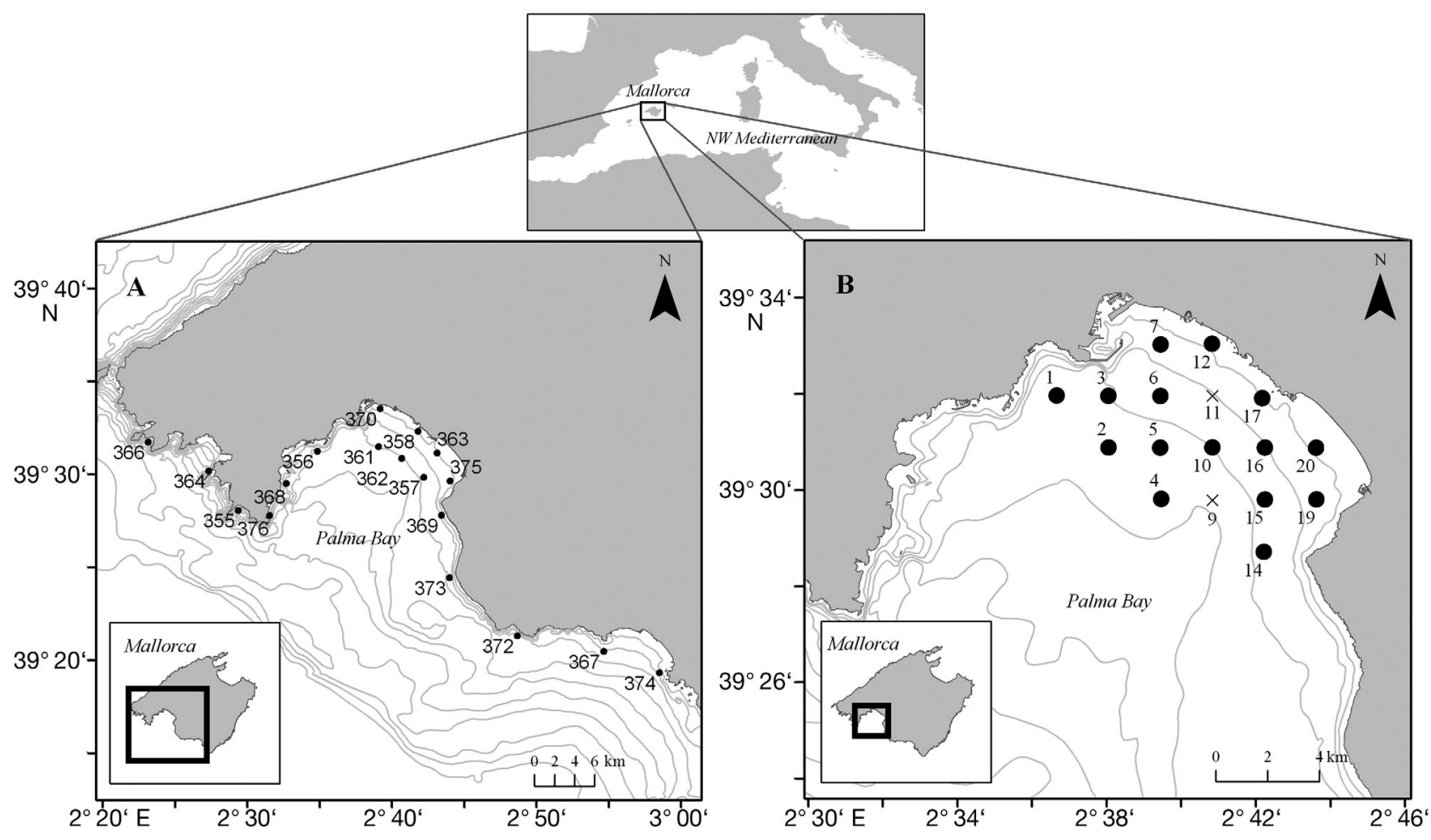

Fig. 1. Receiver array deployed in (A) 2010 (acoustic tracking experiment 1, $\mathrm{ATE}_{1}$ ) and (B) 2011 (ATE $)$ ). O: receiver locations; $\mathrm{x}$ : damaged receivers (no. 9 and 11). The isobaths each represent $10 \mathrm{~m}$ 
Vrgoc 2004). A preliminary study covering a wide spatial range $\left(\mathrm{ATE}_{1}\right)$ was carried out between May and July 2010 (Fig. 1A) because no prior information on movement extent was available for Loligo vulgaris. In accordance with the results obtained in $\mathrm{ATE}_{1}$, a second experiment $\left(\mathrm{ATE}_{2}\right)$ was completed between December 2010 and March 2011 (Fig. 1B).

In both of the experiments, an array of omni-directional acoustic receivers (Sonotronics ${ }^{\circledR}$ SUR-1) was deployed (Fig. 1). In $\mathrm{ATE}_{1}$, a wide array distributed along the south of the island was designed to determine the broad scale of movements (Fig. 1A). The distances between the receivers ranged from 2.6 to $8.9 \mathrm{~km}$. The receivers were placed from $8 \mathrm{~m}$ depth (only 1 receiver) up to $30 \mathrm{~m}$ depth (Fig. 1A). A denser array covering only the main fishing grounds in Palma Bay was deployed during $\mathrm{ATE}_{2}$ (Fig. 1B). The SURs were placed at the nodes of a $1 \times 1 \mathrm{~km}$ grid. The receivers were placed at depths ranging between 8 and $38 \mathrm{~m}$ (Fig. 1B). The number of receivers used was 18 during $\mathrm{ATE}_{1}$ and 17 during $\mathrm{ATE}_{2}$. As the probabil- ity of detection may be a function not only of the distance between receiver and transmitter but also of depth (Claisse et al. 2011), the probability of detection at different distances was estimated at 3 different depths $(10,30$, and $50 \mathrm{~m})$ using control tags moored at prefixed distances from the receivers. Detection probability was assumed to follow a binomial distribution, and data were fitted to a generalized linear model (GLM, glm function in the R package; depth was considered a categorical factor). After the expected battery life of the tags had expired (see details below), we retrieved the receivers and downloaded the data.

\section{Acoustic tagging}

In total, 26 squid were tagged (Table 1) and released inside the receiver array, with 6 individuals during $\mathrm{ATE}_{1}$ and 20 during $\mathrm{ATE}_{2}$ (Fig. 1). Most of the individuals $(\mathrm{n}=23)$ were tagged using the miniature

Table 1. Loligo vulgaris. Tagged squid and tags used. ATE: acoustic tracking experiment. DML: dorsal mantle length. M: male; F: female. TP: period between the release date and last detection in days. DD: total number of days detected. All individuals

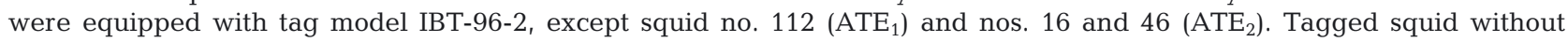
detections during the experiments are shaded grey (nd: no data for these squid). All of the females were fertilized

\begin{tabular}{|c|c|c|c|c|c|c|c|c|c|c|}
\hline & $\begin{array}{l}\text { Squid } \\
\text { code }\end{array}$ & $\begin{array}{l}\text { DML } \\
(\mathrm{mm})\end{array}$ & Sex & $\begin{array}{l}\text { Tag frequency } \\
(\mathrm{Khz})\end{array}$ & $\begin{array}{l}\text { Tag interval } \\
\text { (ms) }\end{array}$ & $\begin{array}{l}\text { Tag \& release date } \\
\text { (dd/mm/уyуy) }\end{array}$ & $\begin{array}{c}\text { Total } \\
\text { detections }\end{array}$ & $\begin{array}{l}\text { No. of } \\
\text { receivers }\end{array}$ & $\begin{array}{l}\mathrm{TP} \\
\text { (d) }\end{array}$ & $\begin{array}{l}\text { DD } \\
\text { (d) }\end{array}$ \\
\hline \multirow[t]{6}{*}{$\mathrm{ATE}_{1}$} & 107 & 276 & M & 70 & 900 & $29 / 04 / 2010$ & nd & nd & nd & nd \\
\hline & $108-10$ & 222 & $\mathrm{~F}$ & 71 & 910 & $26 / 05 / 2010$ & 409 & 2 & 22 & 8 \\
\hline & $109-10$ & 277 & M & 72 & 920 & 06/05/2010 & nd & nd & nd & nd \\
\hline & 110 & 330 & M & 73 & 930 & 03/06/2010 & 1104 & 1 & 10 & 6 \\
\hline & 111 & 276 & M & 74 & 940 & $27 / 04 / 2010$ & 1204 & 2 & 31 & 13 \\
\hline & 112 & 293 & M & 70 & 1040 & $20 / 05 / 2010$ & 139 & 4 & 14 & 6 \\
\hline \multirow[t]{20}{*}{$\mathbf{A T E}_{2}$} & 2 & 217 & F & 70 & 860 & 04/01/2011 & nd & nd & nd & nd \\
\hline & 3 & 205 & $\mathrm{~F}$ & 71 & 890 & $14 / 01 / 2011$ & nd & nd & nd & nd \\
\hline & 4 & 223 & F & 72 & 880 & 04/01/2011 & 1319 & 2 & 14 & 12 \\
\hline & 5 & 205 & $\mathrm{~F}$ & 73 & 910 & $18 / 01 / 2011$ & nd & nd & nd & nd \\
\hline & 7 & 193 & M & 75 & 930 & $24 / 01 / 2011$ & 16 & 2 & 5 & 4 \\
\hline & 8 & 215 & $\mathrm{~F}$ & 76 & 920 & $05 / 02 / 2011$ & 232 & 2 & 13 & 6 \\
\hline & 9 & 240 & $\mathrm{~F}$ & 77 & 950 & $19 / 01 / 2011$ & nd & nd & nd & nd \\
\hline & 10 & 205 & $\mathrm{~F}$ & 78 & 940 & $24 / 01 / 2011$ & 630 & 2 & 9 & 4 \\
\hline & 11 & 230 & M & 79 & 970 & $19 / 01 / 2011$ & 15 & 1 & 7 & 1 \\
\hline & 16 & 250 & M & 69 & 1030 & $10 / 01 / 2011$ & nd & nd & nd & nd \\
\hline & 46 & 250 & $\mathrm{~F}$ & 69 & 970 & 18/01/2011 & 2378 & 2 & 14 & 13 \\
\hline & 47 & 175 & M & 70 & 980 & 04/01/2011 & 378 & 4 & 17 & 6 \\
\hline & 48 & 230 & $\mathrm{~F}$ & 71 & 990 & $07 / 01 / 2011$ & nd & nd & nd & nd \\
\hline & 77 & 230 & $\mathrm{~F}$ & 70 & 920 & $11 / 01 / 2011$ & 491 & 1 & 2 & 2 \\
\hline & 78 & 209 & M & 71 & 930 & 04/01/2011 & nd & nd & nd & nd \\
\hline & $79^{a}$ & 220 & M & 72 & 940 & $07 / 01 / 2011$ & 57813 & 1 & 60 & 59 \\
\hline & 107 & 193 & $\mathrm{~F}$ & 70 & 900 & $13 / 01 / 2011$ & 66 & 2 & 7 & 6 \\
\hline & 108-11 & 191 & $\mathrm{~F}$ & 71 & 910 & 11/01/2011 & 66 & 2 & 4 & 2 \\
\hline & $109-11$ & 246 & M & 72 & 920 & $10 / 01 / 2011$ & nd & nd & nd & nd \\
\hline & 139 & 175 & $\mathrm{~F}$ & 72 & 860 & $12 / 01 / 2011$ & 388 & 2 & 4 & 3 \\
\hline
\end{tabular}

${ }^{\text {a }}$ This squid gave an almost constant number of detections during the $60 \mathrm{~d}$ of tracking. We assumed that it had died near receiver 6 just after it was released and did not consider it in the analysis 
tag IBT-96-2 (Sonotronics ${ }^{\circledR} ; 25 \mathrm{~mm}$ in length; $9.5 \mathrm{~mm}$ in diameter; weight in water: $2.5 \mathrm{~g}$; expected lifespan: $60 \mathrm{~d}$ ). Three individuals were tagged using the acoustic tag CT-82-1-E (Sonotronics ${ }^{{ }^{\circ}}$; size: $38 \times$ $15.6 \mathrm{~mm}$; weight in water: $6 \mathrm{~g}$; expected lifespan: $60 \mathrm{~d})$. The transmitters were activated just before being implanted, and the acoustic tags never exceeded $1.57 \%$ of the squid's body weight.

A specific sequence of beeps, with specific between-beep intervals and at a specific frequency allowed unambiguous squid identification (Table 1). A detection event was registered after a receiver detected a full sequence of beeps. Any detection event was labeled with an ID code, date (mm/dd/yyyy), hour (hh:mm:ss), frequency ( $\mathrm{kHz}$ ), and interval period (ms). A tolerance interval of $5 \mathrm{~ms}$ was selected for detecting and removing putative false detections, following the conservative criteria proposed by Sonotronics (see Sonotronics Unique Pinger ID Algorithm; www.sonotronics.com/) and adopted by other studies that used the same tracking equipment in the same area (March et al. 2010, 2011, Alós et al. 2011).

The squid were caught at sunset using line jigging (Fig. 2A). Our fishing and handling protocols (O'Dor et al. 1995, Gonçalves et al. 2009) minimized the stress and damage to the squid. The squid were immediately sexed, the dorsal mantle length (DML) was measured, and the squid were gently placed on a damp cloth where they were tagged (Fig. 2B,C). Sex was determined by observation of the hectocotylus (Ngoile 1987). Fertilized females were identified by the presence of spermatophores, a small white spot in the ventral buccal membrane (Ngoile 1987, Rasero \& Portela 1998). Tag losses were minimized by gluing 2 hypodermic needles laterally to the tips of the tag (Fig. 2D). This procedure secures the tag inside the squid's ventral mantle cavity (Downey et al. 2009). The tags were inserted at the middle-ventral mantle cavity, using a plastic pistol designed to avoid ripping the squid skin. Special care was taken to avoid piercing any organ with the hypodermic needles and to allow the correct seal of the mantle through the cartilages (O'Dor et al. 1995, Downey et al. 2009; Fig. 2F). Before sliding the tag inside a squid, a silicon washer was placed on the needles to protect the inner part of the mantle. The needles pierced the thickness of the mantle and were secured on the outside of the squid with a silicon washer and metal crimps (O'Dor et al. 1995; Fig. 2G). The full process of biological sampling and tagging lasted
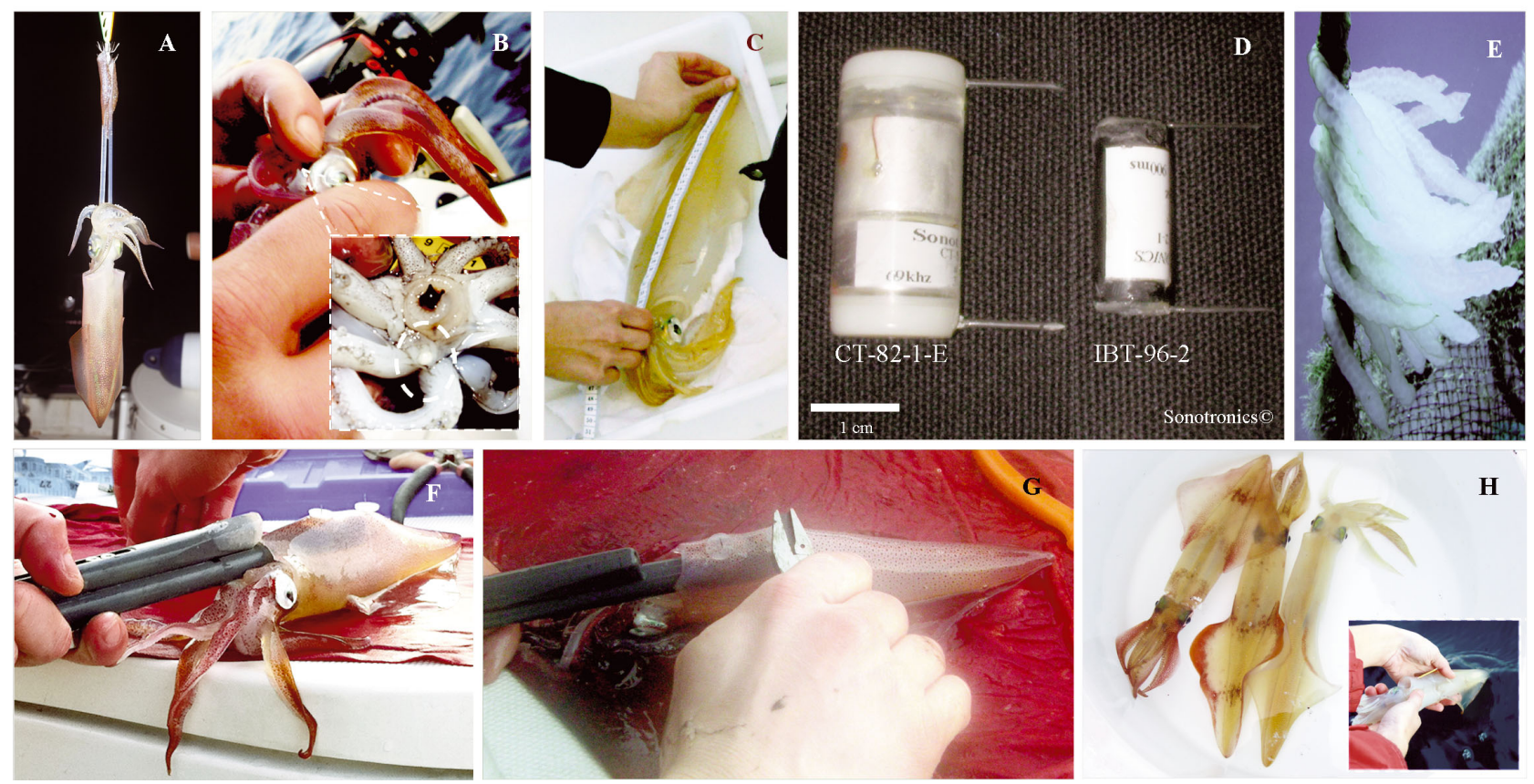

H

Fig. 2. Loligo vulgaris. Acoustic tracking logistics and methods. (A) Squid fished by line jigging. (B) Determination of squid sex and fertilization (in females). Inset details the presence of a spermatophore in the ventral buccal membrane (dashed oval). (C) Dorsal mantle length measurement to the nearest $5 \mathrm{~mm}$. (D) Acoustic tags used in the experiments with sterile hypodermic needles attached laterally to the tags. (E) An egg clutch attached to a receiver rope. (F) Location of the acoustic transmitter. (G) Silicon washers, which were pushed onto the ends of the hypodermic needles and slipped over each needle. The metal cylinder was crimped using pliers to avoid loss of the transmitter. $(\mathrm{H})$ Tagged squid in an open seawater tank on the boat. Inset shows the squid released in a tail-first direction favoring the output of air bubbles present in the mantle cavity 
$<2 \mathrm{~min}$. The tagged squid were placed into a $100 \mathrm{l}$ seawater tank until they recovered and showed the typical fin beating and swimming. The squid were then released at the same location where they were captured (Fig. 2H).

A number of preliminary trials were completed under controlled laboratory conditions to (1) improve the handling of squid and to reduce the tagging time, (2) evaluate the viability of different tags in relation to squid size, and (3) confirm that normal behavior (swimming and feeding) is recovered after tagging.

\section{Fishing effort and egg abundance}

The spatial distributions of the fishing effort of the 2 recreational fishing methods, line jigging and trolling, were determined using visual censuses. Palma Bay was sampled 3 times per month during 2009. The GPS position, fishing mode, and numbers of anglers per boat were recorded for any intercepted boat (unpublished data obtained by the CONFLICT research project CGL2008-958). The boat positions were mapped to explore the spatial distribution of recreational fishers.

Squid egg clutches were found on a relatively large number of receivers when the receivers were recovered. The egg clutches were placed at the knots of the rope, above and below the receiver (Fig. 2E). This unexpected finding allowed us to use the number of egg clutches as a proxy for the spatial distribution of spawning.

\section{Data analyses}

Data from the receivers were downloaded from the SURs as text files, and an appropriate MS Access database was developed to manage these data. This database allowed for the removal of false detections and was used to obtain plots of the spatial and temporal distribution of the receptions (March et al. 2010). The number of detections $h^{-1}$ (chronograms) was plotted for each squid. The day-specific timing of sunrise and sunset (US Naval Observatory; Astronomical Applications Department; http://aa.usno. navy.mil) were overlaid on the chronograms. Moreover, to test for differences between day and night in the number of detections (activity pattern), a generalized linear mixed model (GLMM) was applied (Bates \& Maechler 2010). The statistical unit chosen was the 'visit event'. A visit event of a specific squid was defined as a set of consecutive detections registered by the same receiver (Stark et al. 2005). Two or more detections were considered 'consecutive', and thus, we assumed that they belonged to the same visit event when there was $<1 \mathrm{~h}$ between them. When the time between 2 consecutive detections was $>1 \mathrm{~h}$, we assumed that they indicated 2 separate visit events. Similarly, when a squid was detected by 2 receivers, 2 independent visit events were assumed to occur. The visit events were categorized as either a 'detection peak' $(<4 \mathrm{~h}$ between the first and last detection of the same visit event) or 'detection cluster' ( $>4 \mathrm{~h}$ between the first and last detection of the same visit event). Moreover, in accordance with the results of the experiment of detection range (see Results), only the visit events recorded from the receivers deployed at 25 to $30 \mathrm{~m}$ depth were included in the GLMM, in an attempt to remove any effect of depth on the probability of detection. These receivers accumulated $97.83 \%$ of the visit events.

The goal was to differentiate between highly active movement (detection peak; the squid quickly crossed near a receiver) and slower movement (detection cluster; the squid spent more time within the detection range of the same receiver). A binomial logistic model was assumed; the response variable was 0 when the visit event was a detection peak and was 1 otherwise. The putative explanatory variable was daytime versus nighttime (categorical variable; nighttime included sunrise and sunset). The identity of the squid was treated as a random factor to account for variation at the individual level and to avoid pseudoreplication. This GLMM was fitted using the lme4 library from the $\mathrm{R}$ data analysis software package (www.r-project.org/). A p-value of 0.05 was chosen a priori as the critical level for a rejection of the null hypothesis.

The number of detections and the number of egg clutches corresponding to different bathymetric depth intervals were compared using box plots. The number of intervals considered and their limits were selected to ensure that all of the intervals included a large enough number of receivers. The squid tracks were also plotted; the maps were produced using the $\mathrm{R}$ package and improved using ArcGIS.

\section{RESULTS}

\section{Detections}

The results of the preliminary experiment aimed at exploring the effects of depth and distance to the receiver showed significant differences in the proba- 
bility of detection among depths (probability increased with depth; GLM $\mathrm{p}<0.001$, Fig. 3). This result was similar to those reported by Claisse et al. (2011). However, the distance at which probability of detection was 0.5 was similar, especially when comparing the results obtained at 10 and $30 \mathrm{~m}$ depth (distance to receiver: 97 and $100 \mathrm{~m}$, respectively; at $50 \mathrm{~m}$ depth, this distance increases to $120 \mathrm{~m}_{\text {; Fig. 3). This }}$ result strongly supports that despite some depth effects, the detection probability was virtually the same at low and intermediate depths. Additionally, given these results, the simultaneous reception of the same acoustic signal by more than 1 receiver was highly improbable.

A total of 8835 true detections from 15 squid, out of the 26 tagged individuals, were downloaded. The number of detections of each squid ranged between a minimum of 15 (squid 11) and a maximum of 2378 for squid 46 (Table 1). The total period (TP) over which a squid was detected, defined as the number of days from the tagging day to the last day a squid was detected, ranged from 2 (squid 77) to $31 \mathrm{~d}$ (squid 111 ), mean $\pm \mathrm{SD}=11.53 \pm 7.73 \mathrm{~d}$. The number of days that a squid was detected (DD) varied from 1 (squid 11) to $13 \mathrm{~d}$ (squid 111 and 46), mean $\pm \mathrm{SD}=6.13 \pm$

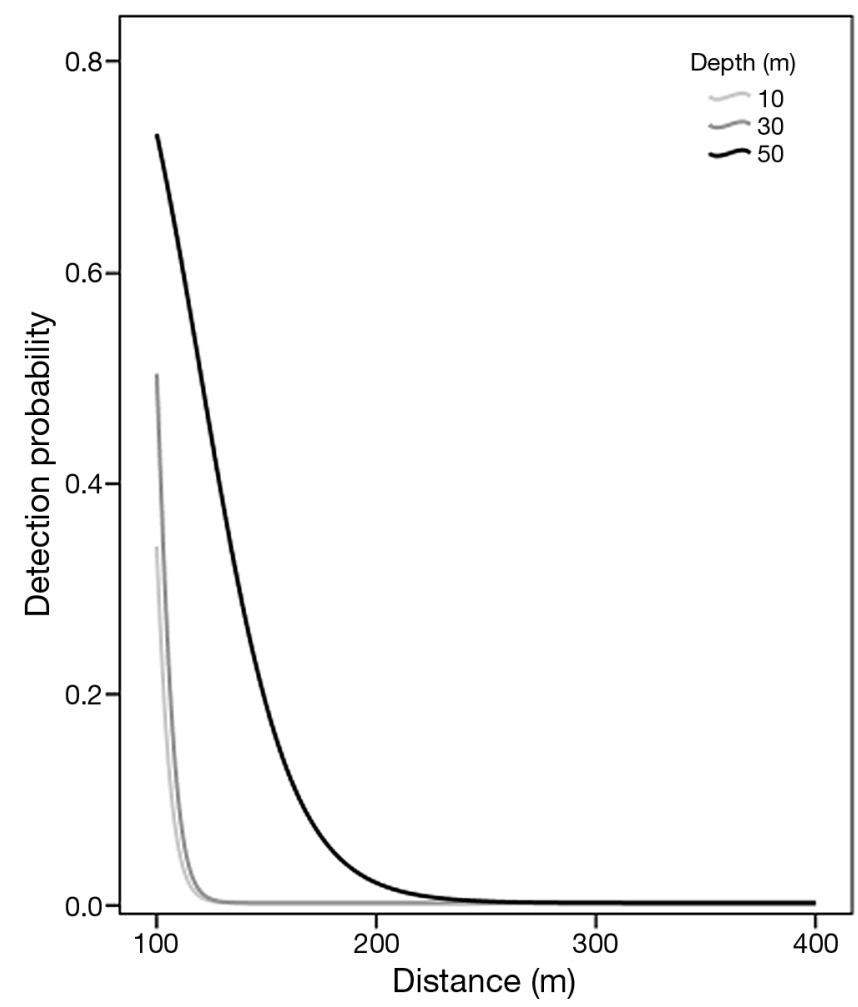

Fig. 3. Loligo vulgaris. Detection probability against distance to the receiver at different depths obtained from the detection range test
$3.88 \mathrm{~d}$. The average number of receivers that detected the same squid was $2.06 \pm 0.88$ and ranged from 1 (squid 110, 11, 77) to 4 (squid 112 and 47). The specific data for the squid are detailed in Table 1.

\section{Temporal pattern}

A preliminary inspection of the time series of the number of detections per time unit did not reveal any clear pattern. However, the definition of the 2 types of visit event, detection peaks and detection clusters, demonstrates the existence of significant differences between day and night (GLMM $\mathrm{p}<0.001$, Fig. 4). During the daytime, the squid tended to remain undetected, and very few visit events took place. However, in those cases, the detections tended to form a detection cluster. In some cases, a detection cluster even lasted most of the day (see examples in Fig. 4). Conversely, such long detection clusters of the same squid on the same receiver were nearly absent between sunset and sunrise. During the nighttime, the visit events tended to be shorter (detection peaks instead of detection clusters; see examples in Fig. 4). Moreover, new appearances, when a specific squid was detected by 2 different receivers within the same day, took place more frequently during the nighttime (squid 112 and 47; stars in Fig. 4).

\section{Space use}

The number of detections was higher between 25 and $30 \mathrm{~m}$ of depth (Figs. $5 \& 6$ ). We noted some effects of depth on detection probability, thus our results must be interpreted with some caution. However, some patterns clearly emerge and seem robust against the small effects of depth. All of the squid were detected within the 25 to $30 \mathrm{~m}$ depth range (examples of squid tracks are shown in Fig. 5). Almost all $(99.9 \%)$ of the detections during $\mathrm{ATE}_{1}$ were made at this depth range, although it is important to note that $61 \%$ of the receivers were deployed at this depth range. Similarly, most of the detections $(5935,99.26 \%)$ corresponded to the 25 to $30 \mathrm{~m}$ depth interval during $\mathrm{ATE}_{2}$. Squid 110, 11, and 77 were detected by only 1 receiver that was placed at a depth range of 25 to $30 \mathrm{~m}$. Most of the remaining squid $(80 \%)$ were also detected in this depth range. Nearly half of the squid moved between 2 closely positioned receivers, but in those cases, they remained within the 25 to $30 \mathrm{~m}$ depth area $(53.33 \%$; 

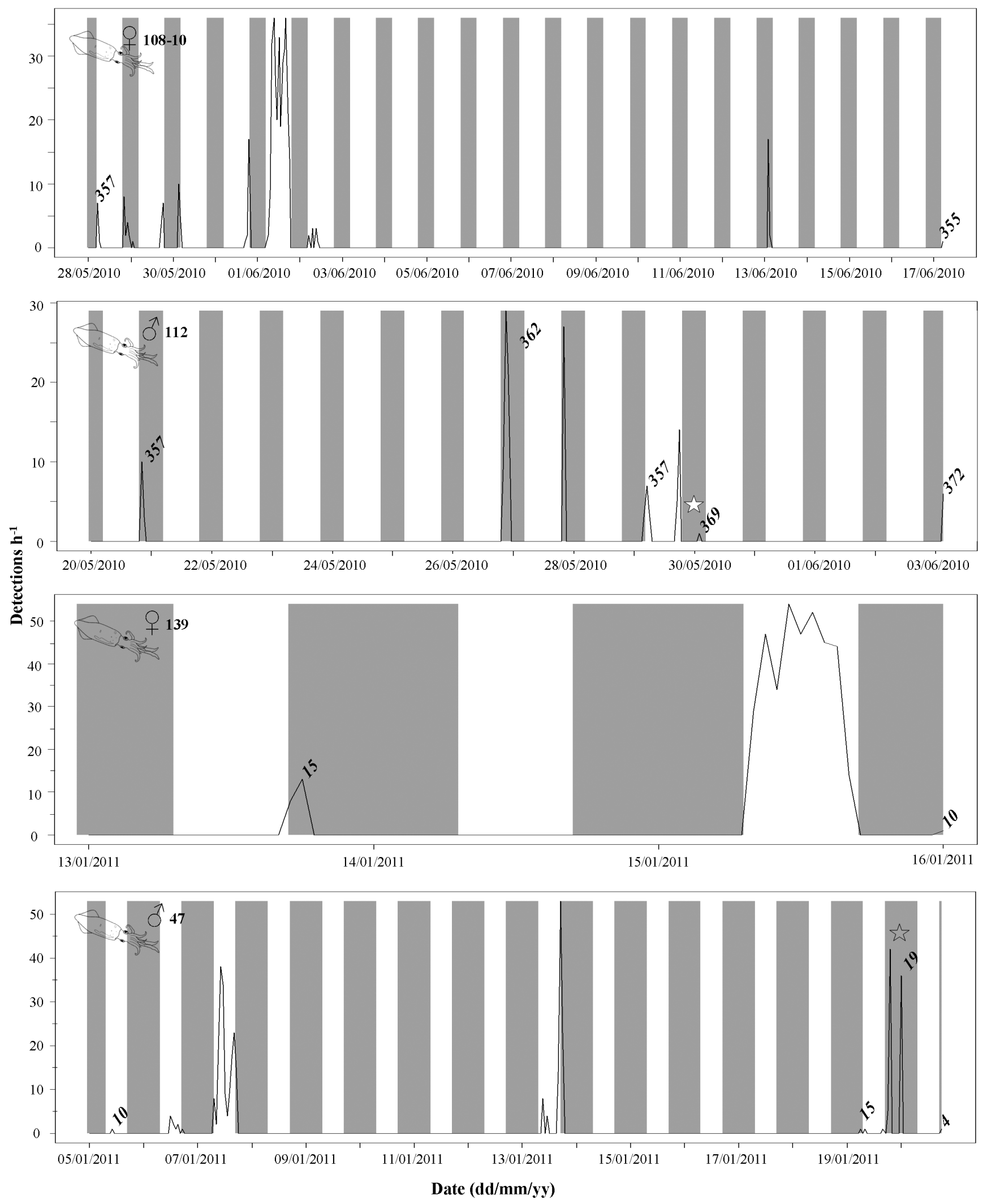

Fig. 4. Loligo vulgaris. Full time series of the detections $\mathrm{h}^{-1}$ of 4 tagged squid from acoustic tracking experiment 1 (ATE ; $_{\text {i }}$ squid 108-10 and 112) and $\mathrm{ATE}_{2}$ (139 and 47). The vertical stripes represent day (white) and night (grey). On the $x$-axis, each mark indicates 00:00 $\mathrm{h}$ of each day. When a squid was detected by another receiver, the new receiver ID is indicated at the first detection. The stars represent the new appearances, when a specific squid was detected by 2 different receivers within the same day 

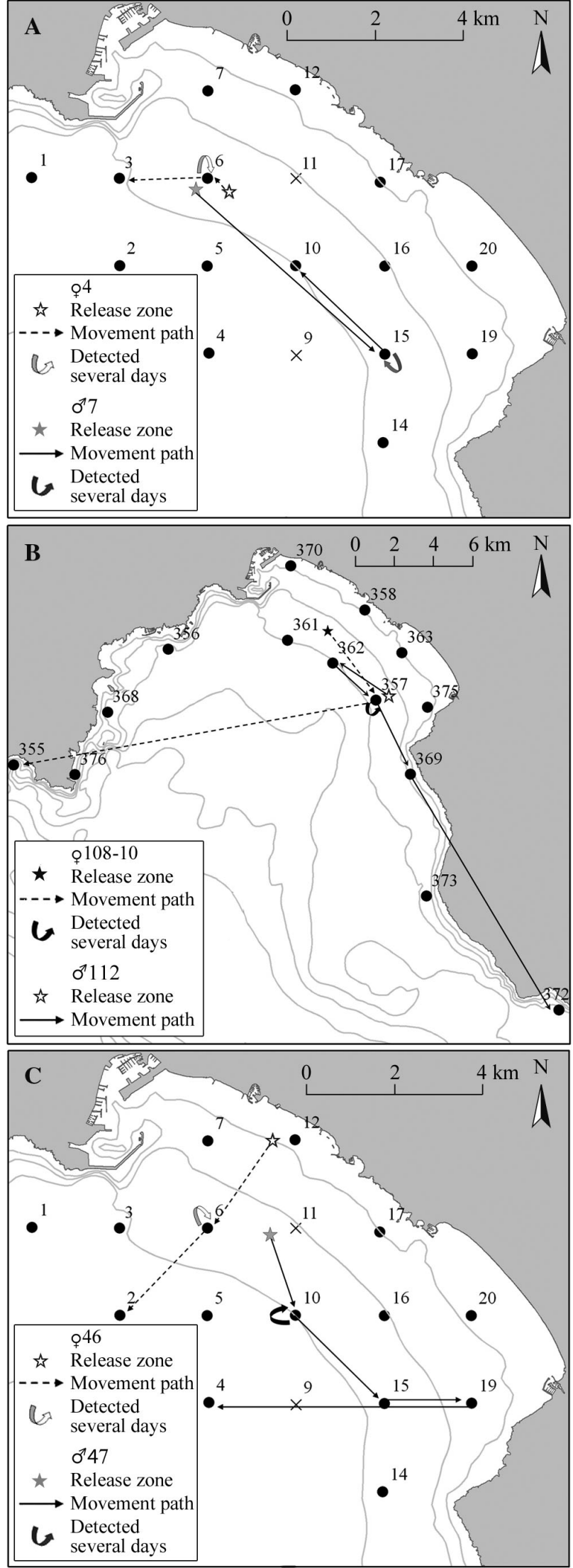

Fig. 5. Loligo vulgaris. Squid tracks assuming the minimum distance traveled (Pecl et al. 2006). For symbols see Fig. 1 legend. (A) Squid nos. 4 and 7, (B) nos. 108-10 and 112, and (C) nos. 46 and 47

e.g. squid 4 and 7 in Fig. 5A). Longer travels were performed by squid 108-10 and 112. Squid 108-10 toured $22.85 \mathrm{~km}$ during the $22 \mathrm{~d}$ of tracking. In the same way, squid 112 traveled $22.2 \mathrm{~km}$ during the $14 \mathrm{~d}$ of tracking. These longer travels were also monitored by receivers deployed in the 25 to $30 \mathrm{~m}$ depth range (Fig. 5B).

During $\mathrm{ATE}_{2}$, squid were also detected by both deeper (31 to $38 \mathrm{~m}$ ) and shallower receivers (16 to $24 \mathrm{~m})$. However, the prevalence of detections outside
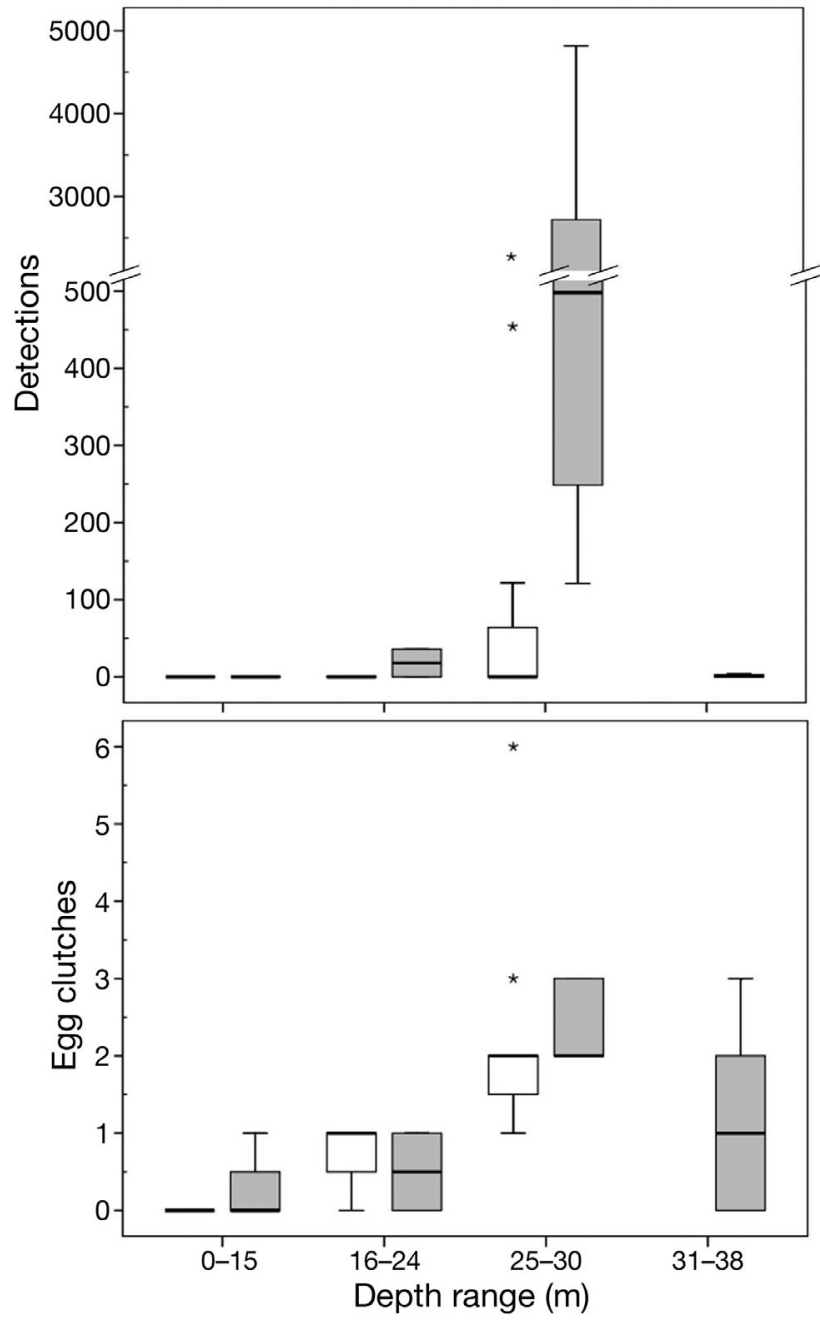

Fig. 6. Loligo vulgaris. Number of detections and egg clutches. White boxes: data from acoustic tracking experiment $1\left(\mathrm{ATE}_{1}\right)$. Grey boxes: data from $\mathrm{ATE}_{2}$. Receivers were not deployed in $\mathrm{ATE}_{1}$ within the depth range of 31 to $38 \mathrm{~m}$. Thick horizontal line $=$ median, box $=25$ th to 75 th percentile range, whiskers $=95 \% \mathrm{CI}$, asterisks $=$ outliers 


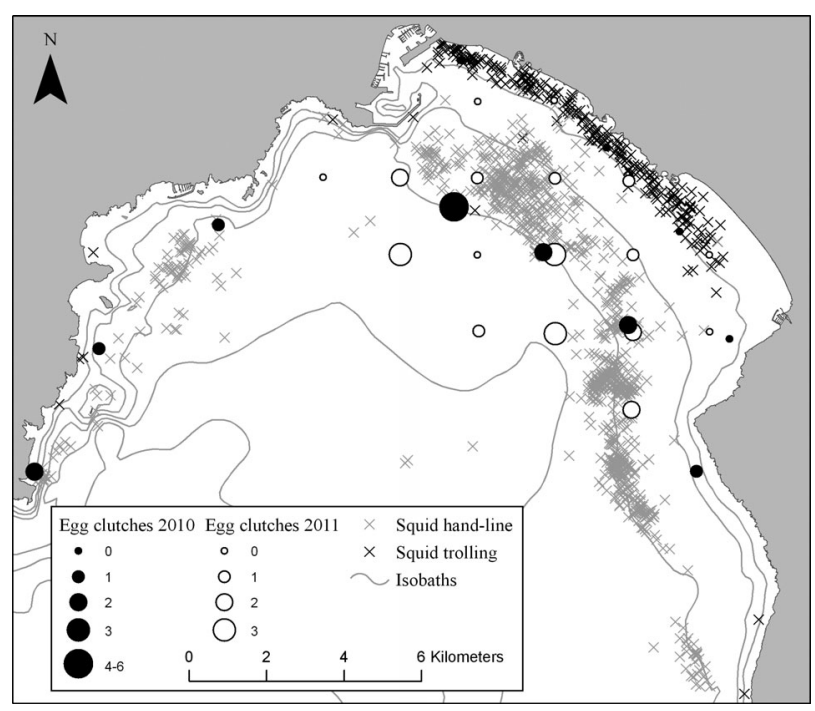

Fig. 7. Spatial distribution of the recreational fishing effort and egg clutch abundance in Palma Bay, Mallorca. The isobaths each represent $10 \mathrm{~m}$

the 25 to $30 \mathrm{~m}$ range was very low $(0.14$ and $0.60 \%$ for deep and shallow receivers, respectively). Squid 47, a male, exemplified such a pattern. It reached receiver 19 at $16 \mathrm{~m}$ depth from receiver 15 at $27 \mathrm{~m}$ depth during the night but left the shallow water before sunrise, and it appeared again in deeper waters at sunset (receiver 4 at $37 \mathrm{~m}$ depth; see the grey star in Fig. 4 and the movement track in Fig. 5C).

No squid were detected by the receivers placed in shallower waters (0 to $15 \mathrm{~m}$ depth), in spite of the fact that some of the squid were tagged and released there. For example, squid 46, a female, was caught, tagged, and released in shallower waters without being detected by receivers deployed in this shallow area. However, this squid was detected $1 \mathrm{~d}$ later at $25 \mathrm{~m}$ of depth, and it spent some days in that area. After that period, this squid left that area at sunset to reach deeper waters at sunrise (receiver 2 at $35 \mathrm{~m}$ depth; Fig. 5C).

In relation to the spatial distribution of the fishing effort, the recreational fishers and part of the commercial fleet concentrated at sunset and in specific areas located between 20 and $35 \mathrm{~m}$ depth. After sunset, the commercial fishers continued to fish at the same fishing ground but using lights, whereas the recreational fishers continued to fish for some time by trolling and focusing almost all of their effort from the shoreline to $10 \mathrm{~m}$ depth, just at the illuminated strip near the city lights (Fig. 7).

The presence of egg clutches was recorded from shallower waters (1 egg clutch at receiver 17 , at $9 \mathrm{~m}$ depth) to deeper waters (3 egg clutches at receiver 9, at $38 \mathrm{~m} \mathrm{depth}$; Figs. $6 \& 7$ ). The number of egg clutches was small (mean $\pm \mathrm{SD}=0.25 \pm 0.5$ ATE $_{2}$ only) on the receivers placed in shallower waters $(0$ to $15 \mathrm{~m}$ ). The receivers deployed at a depth interval between 16 and $24 \mathrm{~m}$ had mean values of $0.67 \pm 0.58$ and $0.5 \pm 0.71$ egg clutches per receiver for $\mathrm{ATE}_{1}$ and $\mathrm{ATE}_{2}$, respectively. All of the receivers that were deployed between 25 and $30 \mathrm{~m}$ had at least 1 egg clutch. The mean number of egg clutches per receiver was clearly higher between 25 and $30 \mathrm{~m}$ $\left(2.18 \pm 1.40\right.$ and $2.40 \pm 0.55$ for $\mathrm{ATE}_{1}$ and $\mathrm{ATE}_{2}$, respectively). Finally, the receivers that were placed at a depth between 31 and $38 \mathrm{~m}$ (only deployed during $\mathrm{ATE}_{2}$ ) had $1.17 \pm 1.17$ egg clutches attached to their structures (Figs. $6 \&$ 7).

\section{DISCUSSION}

Our study provides the first description of the movement patterns of the European squid Loligo vulgaris during inshore spawning aggregations. The conceptual model of movement proposed here is characterized by 2 well-differentiated movement states. The typical daytime movement is characterized by reduced mobility within a narrow area, hereafter referred as the 'day-ground.' The squid tend to remain at a specific day-ground for a long time (most of the daytime of a specific day). However, the location of the day-ground may change between consecutive days. This location may be randomly selected within a larger area. The larger area is delimited by the Palma Bay grounds at 25 to $30 \mathrm{~m}$ of depth. The typical nighttime movement is characterized by increased mobility, i.e. a specific squid spends only a short time at any given location and ranges over a wider area. Such a night-ground possibly covers most of Palma Bay. This diel pattern might be due to periodic daily shifts between reproductive behavior during the day and feeding at night. The empirical evidence supporting this conceptual model emerges from (1) the existence of day-night differences in the detection pattern using acoustic tracking, (2) the spatiotemporal distribution of the fishing effort, and (3) the spatial distribution of egg clutches.

The strongest evidence comes from the day-night differences in the detection pattern. When detected during the daytime, squid tended to remain near the detection range of only 1 receiver in a detection cluster, supporting the hypothesis that the day-ground size is small. However, a specific squid was usually not detected on 2 consecutive days by the same 
receiver, suggesting that the day-ground location may change every day. Almost all of the daytime detection clusters occurred within the 25 to $30 \mathrm{~m}$ depth area of Palma Bay. We propose that the squid may be reproducing during the daytime within a well-defined area. Evidence supporting this specific hypothesis emerges from (1) the spatial distribution of egg clutches in Palma Bay and (2) the fact that the same pattern (i.e. daytime reproduction) has been repeatedly described for other cephalopods.

Concerning the spatial distribution of eggs, other studies suggest that even though egg clutches of Loligo vulgaris have been observed at depths from 2 to $35 \mathrm{~m}$, the clutches were more frequent between 20 and $30 \mathrm{~m}$ (Villa et al. 1997), very close to the 25 to $30 \mathrm{~m}$ depth area reported here. Concerning the daytime reproduction pattern, previous studies demonstrated that during the daytime, $L$. reynaudii remains at the spawning grounds (Sauer et al. 1997, Downey et al. 2009), where it performs a wide range of reproduction behaviors, such as fighting, guarding, sneaking, mating, and egg laying (Hanlon et al. 2002). The same activity pattern has been proposed for the southern calamari squid Sepioteuthis australis Quoy \& Gaimard, 1832, which arrives at sunrise at the vicinity of the spawning grounds and spawns there throughout the daytime (Pecl et al. 2006). Similarly, loliginid squid also showed reproductive activity during the daytime (Sauer et al. 1997, Jantzen \& Havenhand 2003, Forsythe et al. 2004). A plausible and biologically sound explanation is that reproductive behaviors in cephalopods are strongly mediated by visual cues (Hanlon \& Messenger 1996). Specifically, visually detectable body patterning plays an important courtship role during reproduction (Hanlon et al. 1994, 1999, 2002, Hanlon \& Messenger 1996). In fact, intraspecific signaling in squid is known to occur mainly during daylight hours (Hanlon \& Messenger 1996).

During the nighttime, the squid were more mobile. The main empirical evidence supporting this statement is that when detected at night, the squid tended to remain for a short time near a specific receiver, creating detection peaks instead of detection clusters. We propose that Loligo vulgaris may be feeding during the nighttime. Increased activity linked to feeding at night (beginning at dusk) has been described in other squid (O'Sullivan \& Cullen 1983, Hanlon \& Messenger 1996). Specifically, nocturnal predation has been proposed from the results obtained during other acoustic tracking experiments (Sauer et al. 1997, Stark et al. 2005, Downey et al. 2009). The stomachs of $L$. reynaudii caught on the spawning grounds at night contained more food than those caught during the daytime (Sauer \& Lipi ski 1991), supporting an increased predation activity during the nighttime, as in other loliginids.

Additional support for the conceptual model proposed here emerges from the spatiotemporal distribution of the recreational fishing effort. The spatial aggregation of the fishing effort has been adduced as indirect evidence for the spatial distribution of squid (Boyle \& Rodhouse 2005, Pecl et al. 2006, Olyott et al. 2007). In our case, recreational fishing effort using line jigging concentrates between 20 and $35 \mathrm{~m}$ depth during the sunset. We propose that recreational line jigging concentrates within this very narrow spatiotemporal window because squid catchability is higher. This hypothesis is based on the following: (1) squid concentrate during the daytime at 25 to $30 \mathrm{~m}$ depth to form spawning aggregations, and these aggregations probably break down at sunset due to a shift from reproduction to a feeding state (Downey et al. 2009), (2) squid probably feed during the nighttime, thus showing an increased interest for lures, (3) squid display a higher mobility during the nighttime, thus increasing the probability of encountering a lure, and (4) at sunset, sufficient light enables the detection of the lures used in line jigging. Commercial (artisanal) fishers do not stop line jigging after dusk because they can use lights. Recreational fishers may continue to fish after dusk, but only by trolling. The trolling method in shallower waters (from shore to $10 \mathrm{~m}$ depth) is performed by most of the anglers after fishing by line jigging. In accordance with our conceptual model, after dusk squid enlarge their space use from the 25 to $30 \mathrm{~m}$ depth area to a wider area that includes the trolling grounds. This pattern is exemplified by squid 47 (see Figs. 4 \& 5C). We hypothesize that this squid remained in the 25 to $30 \mathrm{~m}$ area during the daytime but became vulnerable to line jigging only at sunset. This squid would also have been vulnerable to trolling after dusk, when it was detected at $16 \mathrm{~m}$ depth, close to the trolling zone.

Acknowledgements. We thank the biologists and friends involved in experimental angling seasons, especially B. Morales-Nin (Mediterranean Institute for Advanced Studies), M. Calvo-Manazza, M. Vidal-Arriaga, J. Maimó, and L. Aguiló. We also thank Albatros Marine Technologies S.L. for the design of the tag pistol. This study was partly financed by the research project CONFLICT (CGL2008-958) funded by the Spanish Ministry of Science and Innovation and by the Acció Especial ‘Determinación de la movilidad y estructura poblacional de la especie diana Loligo vulgaris: aplicación del marcaje acústico y genética poblacional' of the DG Investigación, Desarrollo Tecnológico e Innovación, Conselleria de Innovación, Interior y Justicia, CAIB. M.C.R. received a $\mathrm{PhD}$ fellowship from the Conselleria de Edu- 
cación, Cultura y Universidades (Balearic Island Government) and Fondo Social Europeo (ESF) to conduct research in the Ocean Tracking Network (OTN) at Dalhousie University (Halifax, Nova Scotia, Canada). M.C.R. appreciates the support and hospitality of all OTN staff, mainly E. Walsh and F. Whoriskey, and the suggestions of D. Webber during his research in Canada. We acknowledge the support and suggestions of J. Payne (University of Washington; Pacific Ocean Shelf Tracking). This paper is dedicated to M. OrtizMaldonado.

\section{LITERATURE CITED}

Aitken JP, O'Dor RK, Jackson GD (2005) The secret life of the giant cuttlefish Sepia apama (Cephalopoda): behaviour and energetics in nature revealed through radio acoustic positioning and telemetry (RAPT). J Exp Mar Biol Ecol 320:77-91

Alós J, March D, Palmer M, Grau A, Morales-Nin B (2011) Spatial and temporal patterns in Serranus cabrilla habitat use in the NW Mediterranean revealed by acoustic telemetry. Mar Ecol Prog Ser 427:173-186

Augustyn CJ, Roel BA (1998) Fisheries biology, stock assessment, and management of the chokka squid (Loligo vulgaris reynaudii) in South African waters: an overview. Calif Coop Ocean Fish Invest Rep 39:71-80

Bates DM, Maechler M (2010) lme4: linear mixed-394 effects models using S4 395 classes. R package version 0.999375-36/r1083. Available at: http://R-Forge.R-project. org/projects/lme4/

Botsford LW, Brumbaugh DR, Grimes C, Kellner JB and others (2009) Connectivity, sustainability, and yield: bridging the gap between conventional fisheries management and marine protected areas. Rev Fish Biol Fish 19:69-95

Boyle P, Rodhouse P (2005) Cephalopods: ecology and fisheries. Blackwell Science, Oxford

> Boyle PR, Pierce GJ, Hastie LC (1995) Flexible reproductive strategies in the squid Loligo forbesi. Mar Biol 121: 501-508

Cabanellas-Reboredo M, Alós J, Palmer M, Grädel M, Morales-Nin B (2011) Simulating the indirect handline jigging effects on the European squid Loligo vulgaris in captivity. Fish Res 10:435-440

Claisse JT, Clark TB, Schumacher BD, McTee SA and others (2011) Conventional tagging and acoustic telemetry of a small surgeonfish, Zebrasoma flavescens, in a structurally complex coral reef environment. Environ Biol Fishes 91:185-201

> Downey N, Roberts MJ, Baird D (2009) An investigation of the spawning behaviour of the chokka squid Loligo reynaudii and the potential effects of temperature using acoustic telemetry. ICES J Mar Sci 67:231-243

Dunstan AJ, Ward PD, Marshall NJ (2011) Vertical distribution and migration patterns of Nautilus pompilius. PLoS ONE 6:e16311

Forsythe J, Kangas N, Hanlon RT (2004) Does the Californian market squid (Loligo opalescens) spawn naturally during the day or at night? A note on the successful use of ROVs to obtain basic fisheries biology data. Fish Bull 102:389-392

Gilly WF, Markaida U, Baxter CH, Block BA and others (2006) Vertical and horizontal migrations by the jumbo squid Dosidicus gigas revealed by electronic tagging. Mar Ecol Prog Ser 324:1-17
Gonçalves JM, Poteiro FM, Cardingos F, Martins HR, Pham CK (2009) The Azorean Loligo forbesi (Cephalopoda: Loliginidae) in captivity: transport, handling, maintenance, tagging and survival. Mar Biodivers Rec 2:e120 doi:10.1017/S1755267209001250

González M, Sánchez P (2002) Cephalopod assemblages caught by trawling along the Iberian Peninsula Mediterranean coast. Sci Mar 66:199-208

Guerra A (1992) Mollusca Cephalopoda. Fauna Ibérica, Vol 1. Museo Nacional de Ciencias Naturales, CSIC, Madrid

Guerra A, Rocha F (1994) The life history of Loligo vulgaris and Loligo forbesi (Cephalopoda: Loliginidae) in Galician waters (NW Spain). Fish Res 21:43-69

Guerra A, Sánchez P, Rocha F (1994) The Spanish fishery for Loligo: recent trends. Fish Res 21:217-230

Hanlon RT (1998) Mating systems and sexual selection in the squid Loligo: How might commercial fishing on spawning squids affect them? Cal Coop Ocean Fish Invest Rep 39:92-100

Hanlon RT, Messenger JB (1996) Cephalopod behaviour. Cambridge University Press, Cambridge

- Hanlon RT, Smale MJ, Sauer WHH (1994) An ethogram of body patterning behavior in the squid Loligo vulgaris reynaudii on spawning grounds in South Africa. Biol Bull (Woods Hole) 187:363-372

Hanlon RT, Maxwell MR, Shashar N, Loew ER, Boyle KL (1999) An ethogram of body patterning in the medically and commercially valuable squid Loligo pealei off Cape Cod, Massachusetts. Biol Bull (Woods Hole) 197: 49-62

Hanlon RT, Smale MJ, Sauer WHH (2002) The mating system of the squid Loligo vulgaris reynaudii (Cephalopoda, Mollusca) off South Africa: fighting, guarding, sneaking, mating and egg laying behaviour. Bull Mar Sci 71: 331-345

Iwata Y, Ito K, Sakurai Y (2010) Is commercial harvesting of spawning aggregations sustainable? The reproductive status of the squid Loligo bleekeri. Fish Res 102:286-290

Jantzen TM, Havenhand JN (2003) Reproductive behaviour in the squid Sepioteuthis australis from South Australia: interactions on the spawning grounds. Biol Bull (Woods Hole) 204:305-317

> March D, Palmer M, Alós J, Grau A, Cardona F (2010) Shortterm residence, home range size and diel patterns of the painted comber Serranus scriba in a temperate marine reserve. Mar Ecol Prog Ser 400:195-206

> March D, Alós J, Grau A, Palmer M (2011) Short-term residence and movement patterns of the annular seabream Diplodus annularis in a temperate marine reserve. Estuar Coast Shelf Sci 92:581-587

> Morales-Nin B, Moranta J, García C, Tugores P, Grau AM, Riera F, Cerdà M (2005) The recreational fishery off Majorca Island (western Mediterranean): some implications for coastal resource management. ICES J Mar Sci 62:727-739

Moreno A, Pereira JMF, Arvanitidis C, Robin JP and others (2002) Biological variation of Loligo vulgaris (Cephalopoda: Loliginidae) in the eastern Atlantic and Mediterranean. Bull Mar Sci 71:515-534

> Moreno A, Azevedo M, Pereira J, Pierce GJ (2007) Growth strategies in the squid Loligo vulgaris from Portuguese waters. Mar Biol Res 3:49-59

Ngoile MAK (1987) Fishery biology of the squid Loligo forbesi (Cephalopoda: Loliginidade) in Scottish waters. $\mathrm{PhD}$ thesis, University of Aberdeen 
O'Dor R (2002) Telemetered cephalopod energetics: swimming, soaring and blimping. Integr Comp Biol 42: 1065-1070

O'Dor RK, Hoar JA, Webber DM, Carey FG, Tanaka S, Martins HR, Porteiro FM (1995) Squid (Loligo forbesi) performance and metabolic rates in nature. Mar Freshw Behav Physiol 25:163-177

O'Sullivan D, Cullen JM (1983) Food of the squid Nototodares gouldi in Bass Strait. Aust J Mar Freshw Res 34: 261-285

Olyott LJH, Sauer WHH, Booth AJ (2007) Spatial patterns in the biology of the chokka squid, Loligo reynaudii on the Agulhas Bank, South Africa. Rev Fish Biol Fish 17: 159-172

Payne J, O'Dor RK (2006) Comparing squid optimal cost of transport speeds to actual field migrations: new data from 40-g Loligo opalescens. In: Olsen RJ, Young JW (eds) The role of squid in open ocean ecosystems. GLOBEC Rep 24:16-18

> Pecl GT, Tracey SR, Semmens JM, Jackson GD (2006) Use of acoustic telemetry for spatial management of southern calamary Sepioteuthis australis, a highly mobile inshore squid species. Mar Ecol Prog Ser 328:1-15

Postuma FA, Gasalla MA (2010) On the relationship between squid and the environment: artisanal jigging for Loligo plei at São Sebastião Island $\left(24^{\circ} \mathrm{S}\right)$, southeastern Brazil. ICES J Mar Sci 67:1353-1362

Rasero M, Portela JM (1998) Relationships between mating and sexual maturation of Loligo gahi females in Falkland waters. J Mar Biol Assoc UK 78:673-676

Sánchez P, Guerra A (1994) Bathymetric distribution and

Editorial responsibility: Matthias Seaman, Oldendorf/Luhe, Germany aspects of the life history of Loligo vulgaris in the Catalan Sea (NW Mediterranean). Iberus 12:1-12

Sauer WHH, Lipi ski MR (1991) Food of squid Loligo vulgaris reynaudii (Cephalopoda: Loliginidae) on their spawning grounds off the Eastern Cape, South Africa. S Afr J Mar Sci 10:193-201

Sauer WHH, Roberts MJ, Lipiński MR, Smale MJ, Hanlon RT, Webber DM, O'Dor R (1997) Choreography of the squid's 'nuptial dance.' Biol Bull (Woods Hole) 192: 203-207

Semmens JM, Pecl GT, Gillanders BM, Waluda CM and others (2007) Aproaches to resolving cephalopod movement and migration patterns. Rev Fish Biol Fish 17:401-423

Šifner SK, Vrgoc N (2004) Population structure, maturation and reproduction of the common squid, Loligo vulgaris, in the Central Adriatic Sea. Fish Res 69:239-249

Stark KE, Jackson GD, Lyle JM (2005) Tracking arrow squid movements with an automated acoustic telemetry system. Mar Ecol Prog Ser 299:167-177

Tinbergen L, Verwey J (1945) The biology of Loligo vulgaris Lam. Transl Serv Fish Res Board Can 2733:35

Ulaş A, Aydin I (2011) The effects of jig color and lunar bright on coastal squid jigging. Afr J Biotechnol 10: 1721-1726

Villa H, Quintela J, Coelho M, Icely J, Andrade JP (1997) Phytoplankton biomass and zooplankton abundance in South Portugal (Sagres) with a special reference to the spawning of Loligo vulgaris. Sci Mar 61:123-129

Worms J (1983) Loligo vulgaris. In: Boyle PR (ed) Cephalopod life cycles, Vol 1. Academic Press, London, p 143-158

Submitted: October 12, 2011; Accepted: July 4, 2012

Proofs received from author(s): September 24, 2012 